\title{
Voice mail at the reference desk
}

By Paul Frisch and John J. Small

\section{An alternative to busy signals and long waits on "bold"}

$\mathbf{T}$ he University of Illinois at Chicago (UIC) Main Library's Reference Department has recently adopted a voice mail answering system that allows us to serve clients physically present at the reference desk without the distraction of endlessly ringing telephones, yet maintain our commitment to quality phone service. During FY 1991-92, the reference staff answered 17,312 phone queries. With this new system, the calls are automatically shunted to the voice mail system after the third ring, or when the reference line is busy.

The technology involved in the voice mail system can be complex, but from the client's point of view it functions as an answering machine, albeit a high-tech version. UrC's telecommunications system can accommodate up to 27 simultaneous callers. An individual voice mail account can store a maximum of 48 messages. Each message can be up to four minutes in length. Many other systems and capabilities are available, with costs for full-blown systems ranging from about $\$ 17,000$ to $\$ 500,000 .^{1}$ There are also lower-cost, microcomputer-based voice mail systems, usually operating from a single phone line.

\section{Voice mail alternative}

Once the head of reference decided that voice mail might improve the quality of both in-person and telephone reference, while reducing stress at the Reference Desk, library administration and members of the Reference Depart- ment had to be persuaded to embrace voice mail. Administration asked the department to conduct a small survey to determine whether there was a need for voice mail. The Reference Department recorded the number of phone queries for a typical week. During a five-day period in September 1992 the reference staff handled 492 phone calls. Patron queries concerning library hours and directions accounted for 16.8 percent $^{3}$ of the total; transferals and referrals constituted 24.5 percent; searching the library's catalogs for known items made up 40.4 percent; finally, reference questions were 18 percent of the total number of questions asked.

Reference librarians accustomed to responding to phone queries in real time raised valid concerns about how voice mail might impact the quality of service and the workload. Reference librarians were concerned that the phone queries shunted to voice mail would not receive timely responses. They wanted to know how many times a phone would ring before it went to voice mail and whether a voice mail session could be overridden if a librarian picked up the call after it had entered voice mail. Who would answer voice mail? How often would we respond to the messages? There was some concern over a new reference duty that required additional time, replacing the hurried phone service that took place during the already designated desk duty.

On the positive side, it was hoped that one of the major benefits of voice mail woukd be the ability to continue working with patrons in the library with the knowledge that the voice mail system would handle the telephone overflow in a satisfactory way. In the past, the line would simply ring until the reference staff an-

Paul Friscb is bead of reference at the University of Illinois at Chicago, e-mail: $458257 @ u i c u m . u i c . e d u$; John J. Small is electronic resources librarian at Central Missouri State University, Warrensburg, e-mail: cmsuumb.cmsu.edu 
swered it or until the client no longer had the patience to wait. Neither of these options were viewed as particularly acceptable, because if the line was allowed to ring it may have given the impression that the reference staff were not on duty or were not interested in fielding calls. If a busy reference librarian answered the line, the phone client was often put on hold for an indeterminate period of time. In addition, while the client was on hold, all other callers to the reference line heard a busy signal.

Many calls received at the Reference Desk require forwarding, usually to another library department. The voice mail account would allow us to leave up to a three-minute greeting message for callers, which we initially planned to use in directing callers to the proper library department. An automated attendant feature, another approach to transferring calls, would allow callers to select from a menu of library services and to have their calls forwarded to the appropriate department.

As it has turned out, the only option that we have actually put into effect is the ability to be transferred to a machine that gives the library hours. Limited options and simple instructions may be the best approach to reaching library patrons. Bruce Flanders, a noted automation librarian, points out, "the key to making [new technology] accessible to users is to control your enthusiasm for the technology and to make the system as easy as possible and keep the options limited and the recorded messages brief."

\section{Keep the message clear and brief}

In addition to keeping the recorded message brief, we have learned the importance of removing ambiguity. We are now on the fourth iteration of the message. For the most part, it is the "standard" answering machine message used by many people and places:

"You have reached the Reference Desk at the Main Library of the University of Illinois at Chicago. The reference librarians are unable to answer the phone at this time. Please leave a message, including your entire question, your name, phone number and a time you can be reached, or your CMS user ID number if you wish a reply by e-mail. Your message will be answered in the late morning or mid-afternoon, Monday through Friday. Messages received after 4 o'clock will be answered on the following weekday; messages received on Saturday or Sunday will be answered the following Mon- day. If you want the library hours please press 'zero."

The actual phraseology of the message has turned out to be of more than passing importance. In the first iteration of the message, the phrase "If you want to leave a message" stood in place of "Please leave a message." As a result, clients who chose not to leave a message were holding on the line in the apparent belief that someone would eventually pick up the line if they chose not to leave a message. Once the actual wording had been changed (with some additional vocal emphasis on the phrase, "leave a message"), this problem cleared up almost immediately. We also believe it is important to tell callers when they can expect to have their queries answered in order to reduce user frustration and forestall unrealistic expectations of response time.

\section{Handling voice mail reference queries}

In the first six months, there were a total of 1,995 calls transferred to the voice mail system during regular desk hours when a librarian did not pick up the phone before the fourth ring. Once a call has entered voice mail it cannot be overridden. Callers that transferred to the library hours recording were not counted for technical reasons, while clients calling the Reference Desk after hours are automatically transferred to the hours tape. Hang ups accounted for 876 calls ( 43.9 percent), and 44 callers ( 2.2 percent) did not identify themselves. The Reference Department successfully contacted 907 of the 1,075 callers who identified themselves (84.3 percent). Not surprisingly, 95.5 percent of the identified callers chose phone, rather than electronic mail, as their means of receiving answers to their queries. The 1,075 identified callers left 1,283 queries. Known item searches accounted for 833 queries (64.9 percent), reference questions numbered 299 (23.3 percent), and referrals totaled 151 (11.7 percent).

Voice mail messages are answered Monday through Friday in the late morning and late afternoon. No attempt is made to answer on evenings or weekends because of limited staffing. The department has a voice mail coordinator who assigns voice mail service to our four resident librarians on a rotating basis. It normally takes two to two-and-a-half hours per day to listen to voice mail, find the answers, and respond. This service is counted as public contact hours, and the librarian is accordingly assigned fewer desk hours that day. 


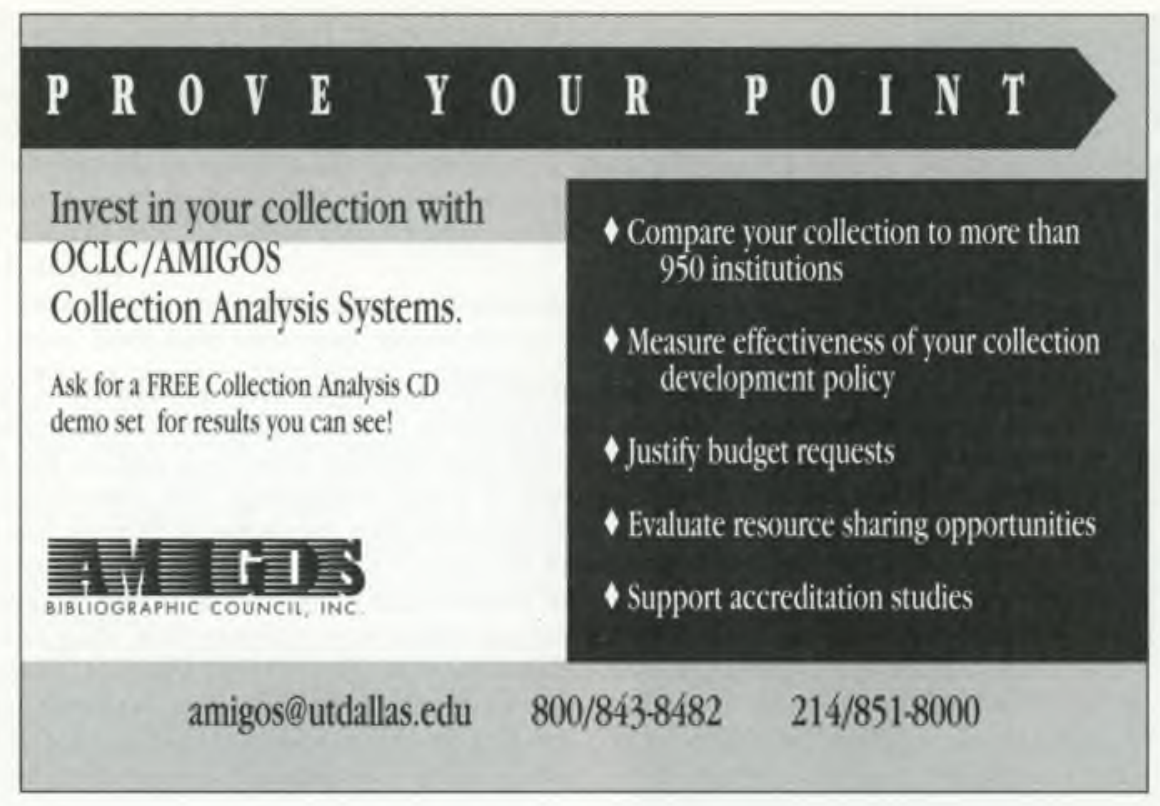

The department has developed two printed forms for voice mail. The first form is for a daily tally of statistics. The second form is a voice mail log. Each identified call is put on a separate log sheet. The information includes caller's name, phone number or e-mail address, name of the responding librarian, date of listening, and whether a.m. or p.m. The respondent writes down the question, sources consulted, and answer. Finally, the librarian notes whether the response was via phone or electronic mail, the times a phone response was attempted (a maximum of four attempts spread over a two-day period), further action to be taken or comments, and whether the message was deleted from voice mail after the transaction was completed.

\section{Conclusions}

Voice mail is a developing technology that will allow reference librarians to continue serving the patrons who are physically present, while allowing contact via telephone to continue. As long as the messages are checked often and answered promptly, users are likely to accept the delayed but assured responses of voice mail. In our experience, there have been more comments about how useful the system is, than there have been negatives. While patrons prefer to speak with a living human being, voice mail offers an alternative to the busy signal that should not be overlooked. In fact, some pa- trons have been identified as "regular callers" to the voice mail system. Voice mail is particularly beneficial to the interactions between reference staff and in-person clients during the busiest portions of the day. A more thorough reference transaction is likely to occur in an environment not driven by the interruptions of ringing phones.

\section{Notes}

1. C. H. Nolan, "Voice messaging technology and library applications," Canadian Library Joumal 49 (June 1992): 217-20.

2. Bruce Flanders, "Voice mail: Enhancing communications," Computers in Libraries 11 (February 1991): 28-29.

3. The Main Library was already operating a recording of the library hours on a separate phone number.

4. Flanders, "Voice mail," 28-29.

\section{Get connected!}

Jobs and news now on the Internet

\section{C\&RL NewsNet}

gopher to "gopher.uic.edu", port 70 